\title{
The influence of crop dryer operation parameters on the efficiency of energy recovery from extract air
}

\author{
Edward Przydróżny ${ }^{1}$, Aleksandra Przydróżna ${ }^{2, *}$, Sylwia Szczęśniak ${ }^{1}$, and Juliusz Walaszczyk ${ }^{1}$ \\ ${ }^{1}$ Wrocław University of Science and Technology, Department of Air Conditioning, Heating, Gas \\ Engineering and Air Protection, ul. Norwida 4/6, 50-373 Wrocław, Poland \\ ${ }^{2}$ Max Fordham, 42-43 Gloucester Cres, Camden Town, London, NW1 7PE, United Kingdom
}

\begin{abstract}
Crop drying, especially maize drying, occurs at low external air temperatures, which are lower than the extract air temperature. Therefore, using heat exchangers, to recover thermal energy from the extract air to preheat the cold and dry external air, results in a significant reduction in the primary energy demand for crop drying. The measurements of air parameters in the crop dryer, with a drying capacity of $19 \mathrm{Mg} / \mathrm{h}$ of maize, confirm the assumptions undertaken for the production of the heat recovery system. We apply the cross-counter-flow surface heat exchanger system to provide a significant improvement in the efficiency of crop drying. We perform the analysis of the thermal energy recovery system operation. Our results indicate the influence of the drying air set-point and the crop specific humidity on the efficiency of energy recovery from the exhaust air. We performed our measurements at different drying air temperature set-points and different crop relative humidity.
\end{abstract}

\section{Introduction}

Crop harvested from fields, especially maize, rarely has a relative humidity suitable for direct storage. Seeds harvested in autumn should usually be dried to the humidity appropriate for their storage. Typically, to dry the crop, the heated air with a low relative humidity is used. This airflow removes moisture as it washes the crop. Various technologies of drying air preparation can be selected; especially the method of air heating can vary. Obtaining energy for heating the drying air is often related to the possibility of using natural sources, e.g. solar energy [1].

Currently, in Poland, industrial crop drying occurs mainly in dryers operating in an open system that use heated external air (heated by e.g. gas burners). In these dryers, the humid air, after assimilating moisture from the grain, is expelled into the atmosphere. To heat the external air, both external (central supplying energy to different recipients) and individual (supplying energy to the dryer only) energy sources can be used. Depending on the availability, solid, liquid and gaseous fuels are used [2,3]. Currently, the gas burned directly

* Corresponding author: aleksandraprzydrozna@gmail.com 
in the drying airflow is used predominantly [4]. This type of air heating provides high efficiency of obtaining energy from gas burning. This is due to the low energy losses during heat transfer from the burnt gas to the heated air. The temperature of heated drying air directly affects the drying efficiency. The maximum air temperature depends on the type of grain and its purpose. Typical drying air temperatures in cross-flow dryers under consideration range from $80-110^{\circ} \mathrm{C}$ [4].

After the hot drying air passes through crop, the air temperature decreases to $45-60^{\circ} \mathrm{C}$, while the moisture content increases to $30-40 \mathrm{~g} / \mathrm{kg}_{\mathrm{da}}$ (gram per kilogram of dry air). Subsequently, humid and warm air, used in the drying process, is usually removed directly outside the dryer. In Poland, the harvest of basic cereals is performed in July and August, whereas the corn harvest occurs in October, November and often in December [5, 6]. The maize grain collected in autumn has typically the highest relative humidity. Simultaneously, the external air temperature is already low. Maize drying under these conditions has the largest energy demand per unit weight of grain. In addition, the drying of maize, with a relative humidity exceeding $40 \%$, often has to be performed in two stages. Humid air, expelled from the dryer, has a high thermal potential and high specific enthalpy, compared to the properties of external air. An attempt to recover energy from exhaust air and delivering it to the heated air seems therefore rational and economically justified. This applies particularly to the autumn period, when the external air temperature is low and the relative humidity of the grain is very high. Under these thermodynamic conditions of air and grains, the external air can be also heated using condensation energy, which arises from the condensation of moisture contained in humid and warm extract air [7]. This can be particularly effective due to the heat of water condensation being many times higher than the specific heat of air. The temperature decrease of warm and humid extract air, from which moisture condensation occurs, is minimal in relation to the increase in the temperature of the heated external air .

We performed measurements of energy recovery from extract air and analysed application of heat recovered to heat the external air, for subsequent drying, in a dryer with a counter-current cross-flow heat exchanger. The measurements were carried out during the maize drying at different temperatures and relative humidity of the drying air.

\section{Method}

Fig. 1. shows the crop dryer (schematic and photo) used during measurements of energy recovery from extract air. Fig. 2. shows a schematic of the dryer with basic equipment and characteristic airflows (drying and extract) marked.
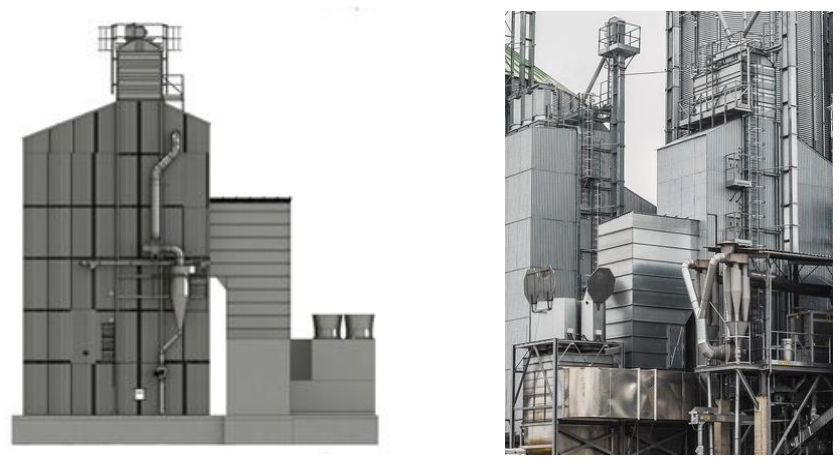

Fig. 1. Grain dryer with a capacity of $20 \mathrm{Mg} / \mathrm{h}$ of dried corn with energy recovery from the extract air [8]. 


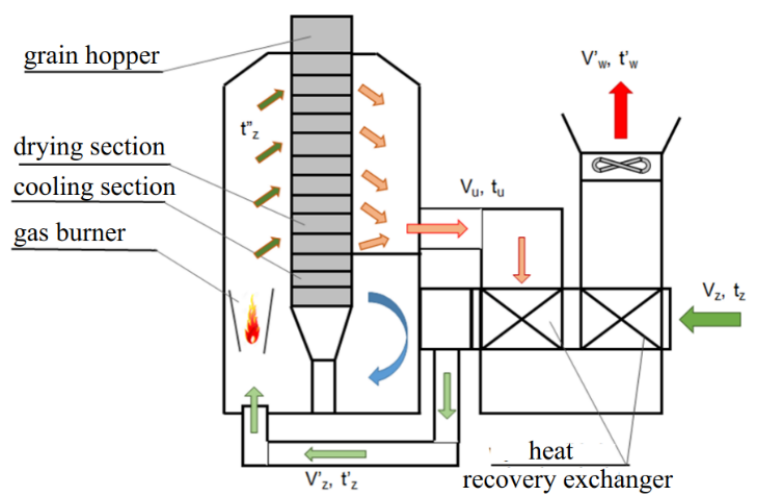

Fig. 2. Schematic of the dryer with the thermal energy recovery from the extract air in the plane heat exchanger with the cross-counter-flow of the drying and extract airflows. Key: $V_{z}$ - external air; $V_{z}^{\prime}$ - preheated external air; $V_{u}$-air removed from the dryer before heat recovery exchangers; $V_{w}^{\prime}$ - exhaust air from the dryer; $t_{z}$ - external air temperature; $t_{z}^{\prime}$ - temperature of pre-heated external air; $t^{\prime \prime}{ }_{z}$ - drying air temperature; $t_{u}$ - the temperature of the air removed from the dryer before heat recovery exchanger; $t^{\prime} w_{w}$ - temperature of the air removed from the dryer after the exchanger [6].

The efficiency of energy recovery from the humid air removed from the dryer, after the drying process, is influenced by the construction and extent of heat exchange surface. The temperature efficiency of energy recovery is defined as:

$$
\eta_{t}=\left(t_{z}-t_{z}\right) /\left(t_{u}-t_{z^{\prime}}\right)
$$

wherein: $t_{z}$ - external air temperature, ${ }^{\circ} \mathrm{C}, t_{z}{ }^{\prime}$ - temperature of pre-heated external air, ${ }^{\circ} \mathrm{C}$, $t_{u}$ - temperature of the air removed from the dryer before heat recovery exchanger, ${ }^{\circ} \mathrm{C}$.

We performed measurements of energy recovery from the extract air from the cross-flow dryer during the maize drying in 2017 and 2018 directly after harvest. The average relative humidity of maize in 2017 was 31\%, whereas in 2018 27\%. The average temperature of heated air at the inflow to dried grains was maintained in 2017 in the range of $125-135^{\circ} \mathrm{C}$, whereas in 2018 in the range of $120-130^{\circ} \mathrm{C}$. The average temperature of humid air after passing through the dried grain, both in 2017 and 2018 , was $60-65^{\circ} \mathrm{C}$. Essentially, as the temperature of the heated drying air rises, the air temperature of the humid air before the energy recovery exchanger increases. The relative humidity of the grain affected the temperature decrease of the air flowing through the grain. As the humidity increased, the temperature drop in the drying air also increased. Our results are based on over 20000 measurements carried out on a continuously-operating dryer.

\section{Results}

We designed our measurements to assess the effect of grain humidity and drying air temperature on the efficiency $€$ of energy recovery from the extract air for heating the drying air. This efficiency $€$ is interpreted as the portion of thermal energy, obtained from the air removed from the dryer to preheat the drying air, relative to the total energy used to heat the air, determined from:

$$
\epsilon=V_{z} \rho_{z} c_{p}\left(t_{z}{ }^{\prime}-t_{z}\right) /\left(V_{z}^{\prime} \rho_{z}^{\prime} c_{p}\left(t_{z}^{\prime \prime}-t_{z}{ }^{\prime}\right)\right)
$$


wherein: $V_{z}$ - external airflow at the inlet to the dryer, $\mathrm{m}^{3} / \mathrm{s}, V_{z}{ }^{\prime}-$ airflow preheated in the energy recovery exchanger at the inlet to the combustion chamber in the dryer, $\mathrm{m}^{3} / \mathrm{s}$, $\rho_{z}$ - external air density, $\mathrm{kg} / \mathrm{m}^{3}, \rho_{z}{ }^{\prime}-$ air density after the exchanger for energy recovery, $\mathrm{kg} / \mathrm{m}^{3}, c_{p}$ - specific heat of air, $\mathrm{kJ} /(\mathrm{kg} \mathrm{K}), t_{z}{ }^{\prime \prime}$ - temperature of the drying air preheated in the gas burner chamber, ${ }^{\circ} \mathrm{C}$.

The temperature efficiency of the exchanger system used for energy recovery during measurements was $\eta=0.6$. However, in the course of operation, it changed in the range from 0.5 to 0.6 depending on the cleanliness of the heat exchange surface, especially on the side of the humid air removed from the dryer. The measurements of the heat flow between the air removed from the dryer and the external air flowing into the dryer were used to simulate the energy recovery efficiency for the extended range of conditions and parameters of the dryer's operation. We perform separate simulations of energy recovery efficiency for 2017 and 2018 assuming: external air temperature ranging from 5 to $20^{\circ} \mathrm{C}$, temperature efficiency of the exchanger for energy recovery ranging from 0.5 to 0.75 , drying air temperature from 125 to $135^{\circ} \mathrm{C}$ for 2017 simulation and from 100 to $115^{\circ} \mathrm{C}$ for 2018 simulation. We used different drying air temperature set-points to ensure that the air temperature at the maize outflow does not exceed $60-65^{\circ} \mathrm{C}$. Results of calculations and simulations are shown in the figures below. Fig. 3. and Fig. 4. show the efficiency of energy recovery from the extract air as a function of the external air temperature and the temperature efficiency of the energy recovery exchanger at different drying air temperatures.
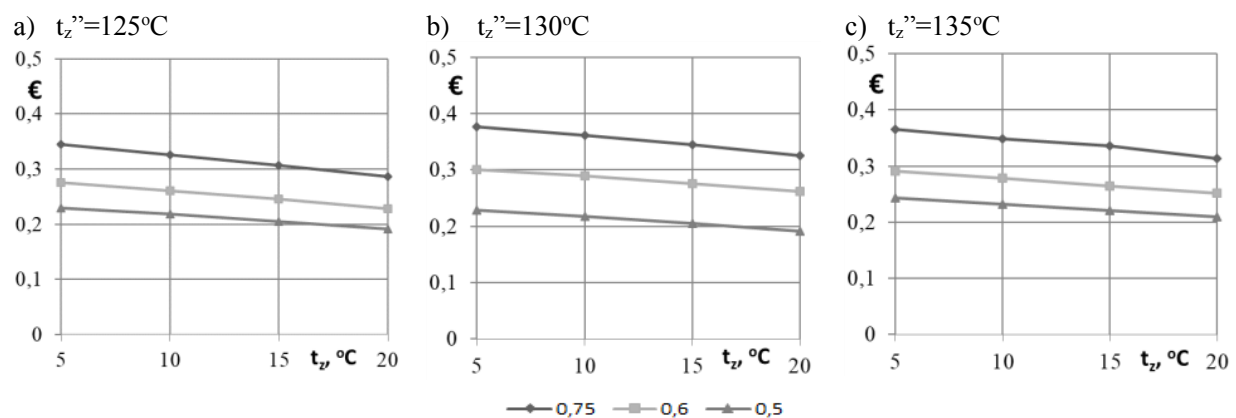

Fig. 3. Energy recovery from the extract air from the dryer as a function of the external air temperature for selected temperature efficiencies of the exchanger for heat recovery $(0.5,0.6$ and 0.75 ) and at constant drying air temperatures, respectively, for $2017:$ a) $t_{z}{ }^{\prime \prime}=125^{\circ} \mathrm{C}$; b) $t_{z}{ }^{\prime \prime}=130^{\circ} \mathrm{C}$ and c) $t_{z}^{\prime \prime}=135^{\circ} \mathrm{C}$.
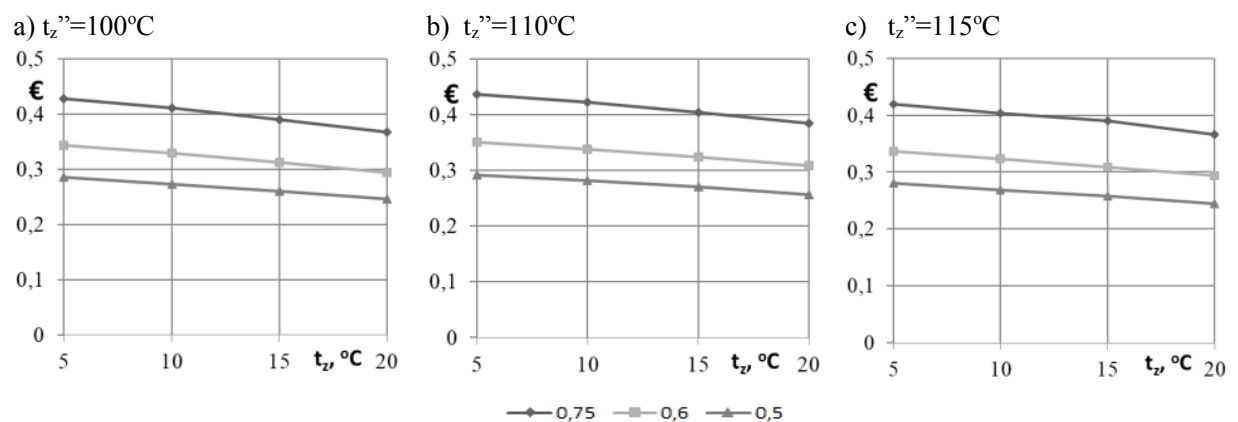

Fig. 4. Energy recovery from the extract air from the dryer as a function of the external air temperature for selected temperature efficiencies of the exchanger for heat recovery $(0.5,0.6$ and 0.75 ) and at constant drying air temperatures, respectively, for 2018 : a) $t_{z}{ }^{\prime \prime}=100^{\circ} \mathrm{C}$; b) $t_{z}{ }^{\prime \prime}=110^{\circ} \mathrm{C}$ and c) $t_{z}{ }^{\prime \prime}=115^{\circ} \mathrm{C}$. 
The graphs in Fig.3. and Fig.4. show that the greatest impact on the efficiency of energy recovery from the extract air from the dryer has the temperature efficiency of heat recovery exchangers. The temperature of the external air also influences the efficiency of heat recovery for heating the external air - the increase in the external air temperature reduces efficiency of heat recovery. Fig. 5. and Fig. 6. show the efficiency of energy recovery from exhaust air depending on the drying air temperature at different external air temperatures and constant temperature efficiency of the heat recovery exchanger.

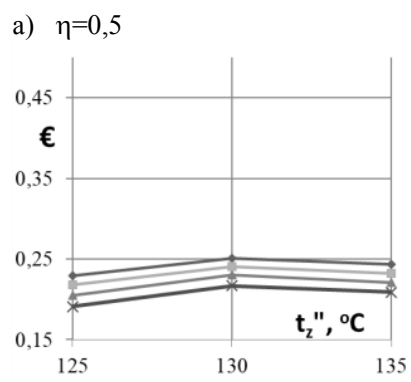

b) $\eta=0,6$

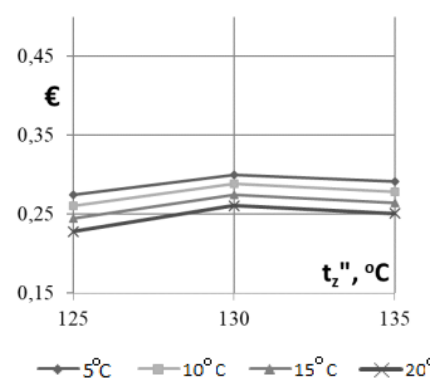

c) $\eta=0,75$

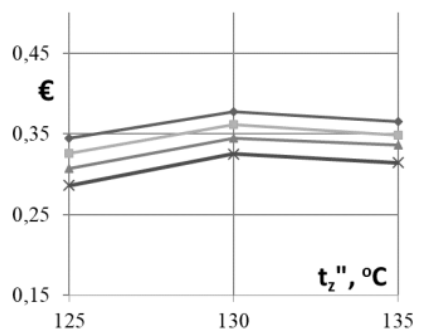

Fig. 5. Efficiency of energy recovery from the extract air from the dryer, depending on the drying air temperature for selected external air temperatures $\left(5^{\circ} \mathrm{C}, 10^{\circ} \mathrm{C}, 15^{\circ} \mathrm{C}\right.$ and $\left.20^{\circ} \mathrm{C}\right)$ and with constant temperature efficiency of the heat recovery exchanger for 2017 measurements: a) 0.5 ; b) 0.6 and c) 0.75 .

a) $\eta=0,5$

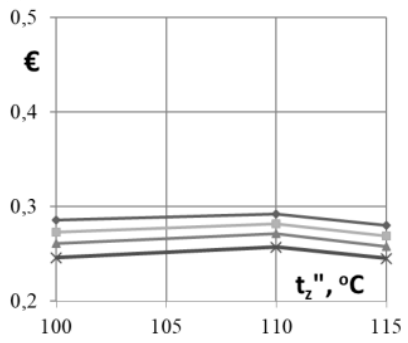

b) $\eta=0,6$

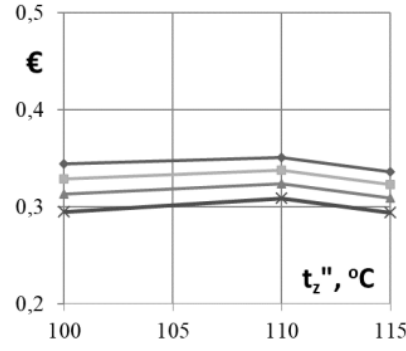

$\rightarrow 5^{\circ} \mathrm{C} \rightarrow-10^{\circ} \mathrm{C} \longrightarrow 15^{\circ} \mathrm{C} \rightleftharpoons 20^{\circ} \mathrm{C}$ c) $\eta=0,75$

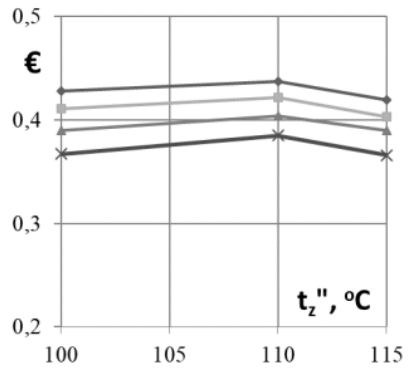

Fig. 6. Efficiency of energy recovery from the extract air from the dryer, depending on the drying air temperature for selected external air temperatures $\left(5^{\circ} \mathrm{C}, 10^{\circ} \mathrm{C}, 15^{\circ} \mathrm{C}\right.$ and $\left.20^{\circ} \mathrm{C}\right)$ and with constant temperature efficiency of the heat recovery exchanger for 2018 measurements: a) 0.5 ; b) 0.6 and c) 0.75 .

Fig. 5. and Fig. 6. show that the temperature of the drying air has a relatively small, but noticeable, effect on the efficiency of the heat recovery from the extract air to heat the drying air. In addition, a specific drying air temperature set-point can be observed, where the maximum heat recovery is utilised to heat the air. As an aside, the significant influence of external air temperature on the efficiency of using recovered energy is confirmed. Fig. 7. shows the effectiveness of using the recovered energy from the extract air in relation to the temperature efficiency of the heat recovery exchanger at different temperatures of external and drying airflows. The graphs shown in Fig. 7. confirm that the thermal efficiency of heat recovery exchanger influences the efficiency of utilisation of energy extracted from humid extract air from the dryer. In addition, both the external air and drying air temperatures have a noticeable effect on this efficiency. 
a)

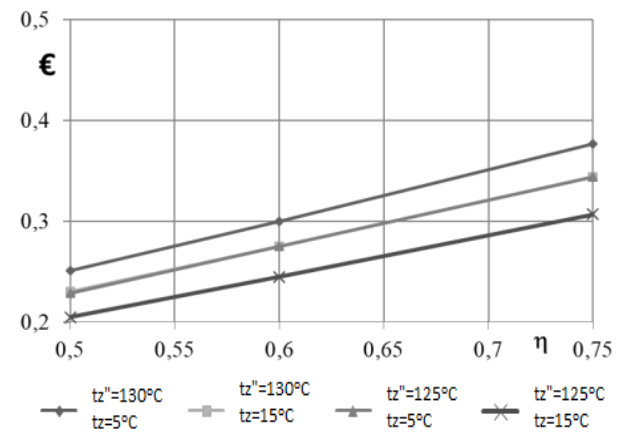

b)

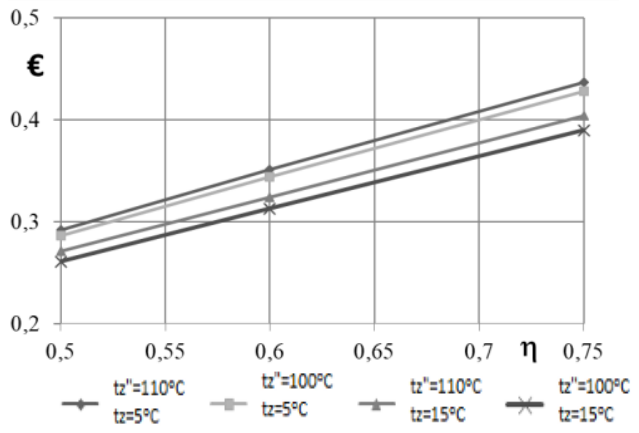

Fig. 7. Effectiveness of heat recovery from the extract air from the dryer as a function of the temperature efficiency of the heat recovery exchangers for selected temperatures of the drying air and external air: a) 2017 measurements, b) 2018 measurements.

\section{Conclusions}

With the mass production of crop, it is necessary to dry crop to the humidity ensuring its proper storage. The crop drying processes are carried out by forced flow of the heated external air, and the exhaust air from the dryer has a temperature higher than the external air temperature. Thus, the use of energy recovery from the humid extract air and its use for preheating the drying air are in line with the common trend of reducing primary energy consumption.

We performed measurements of thermal processes occurring during maize drying during two harvests in 2017 and 2018, respectively. The crop drying processes were carried out during harvesting under the existing weather conditions, different temperatures of the heated drying air and various humidity of the dried maize.

We observed that, for the used system of exchangers for energy recovery, the efficiency of managing the recovered energy allowed for limiting the energy for heating the air by more than $25 \%$, regardless of the operating parameters of the dryer.

The efficiency of managing the recovered energy is influenced by both the temperature of the drying air and the humidity of the dried grain. Both the increase of the drying air temperature and the humidity of the grain lead to increasing the efficiency of the energy recovery.

The efficiency of managing the recovered energy is mainly influenced by the temperature efficiency of the exchangers used for energy recovery. Therefore, during the operation it is necessary to ensure regular cleaning of these heat exchangers, especially the surfaces on the extract air side, on which condensation takes place, and dust and scales are deposited.

This article deals with the wide dissemination of industrial research results in accordance with paragraph 5 of the contract for co-financing the project entitled "Development of an energy-saving dryer with heat recovery and integrated dust collection system" implemented under the Innovative Economy Operational Program, 2007-2013, Priority 1. Research and Development of Modern Technologies, Measure 1.4. Support for target projects. The project was co-financed by the National Centre for Research and Development. Co-financing agreement number: UDA-POIG.01.04.00-02$104 / 12$. 


\section{References}

1. T. B. Johansson, A. P. Patwardhan, N. Nakićenović, L. Gomez-Echeverri (Eds.) Cambridge University Press (2012)

2. U. A. Acasio, R. C. Maxon, S. H. Khan, Food and Feed Grains Institute Manhattan, Kansas 66506-2202, USA (1992)

3. K. J. Chua, J. C. Ho Chou, M. N. A. Hawlader, Drying Technology 20, 8, 1579-1610 (2002)

4. D. E. Maier, F. W. Bakker-Arkema, Proceedings of the 2002 Facility Design Conference of the Grain Elevator \& Processing Society, St. Charles, Illinois, USA (2002)

5. E. Przydróżny, A. Przydróżna, S. Szczęśniak, Instal (2018)

6. E. Przydróżny, S. Szczęśniak, Instal (2019)

7. E. Przydróżny, A. Przydróżna, Proceedings of the VIII International Scientific Agriculture Symposium, Agrosym, Jahorina, Bosnia and Herzegovina (2017)

8. http://www.feerum.pl/pl.suszarnie-do-zboza.html 